Arq. Bras. Med. Vet. Zootec., v.70, n.3, p.815-822, 2018

\title{
Investigação de Salmonella spp. em Psittaciformes exóticos e nativos mantidos em cativeiro na região central do Rio Grande do Sul
}

\author{
[Investigation of Salmonella spp. in exotic and native Psittaciformes kept in captivity in the \\ central region of Rio Grande do Sul]
}

L. Murer, S.R. Didoné, A.B.B. Freitas, M. Lovato

Universidade Federal de Santa Maria - Santa Maria, RS

\begin{abstract}
RESUMO
As doenças infecciosas são reconhecidamente causadoras de declínios populacionais de animais silvestres e algumas delas podem representar ameaça à saúde pública. O presente estudo objetivou investigar a ocorrência de Salmonella spp. em Psittaciformes exóticos e nativos mantidos em cativeiro na região central do Rio Grande do Sul, além de comparar os resultados obtidos por meio do método bacteriológico convencional e da reação em cadeia da polimerase (PCR), mediante a utilização de material fecal do ambiente, evitando-se o estresse da contenção. Durante os meses de agosto/2016 e setembro/2016 foram coletadas amostras de fezes frescas de 90 gaiolas em dois criatórios, representando 180 aves. Com as duas técnicas empregadas nas análises, as amostras foram negativas para Salmonella spp., contudo foram detectadas bactérias da família Enterobacteriaceae: Escherichia coli, Cedecea sp. e Citrobacter freundii. Considera-se importante a continuidade do monitoramento dos criatórios, já que o patógeno investigado pode estar em aves portadoras e se manifestar em situações de estresse, representando riscos enquanto zoonose e prejuízos à saúde das aves.
\end{abstract}

Palavras-chave: aves silvestres, psitacídeos, patógenos intestinais, Enterobacteriaceae, zoonoses

\begin{abstract}
Infectious diseases are known to cause decline in wildlife population and some of them may represent a threat to public health. This study aimed to investigate the occurrence of Salmonella spp. in exotic and native Psittaciformes kept in captivity in the central region of Rio Grande do Sul, Brazil, and to comparing the results obtained through the conventional bacteriological method and the polymerase chain reaction (PCR), using fecal matter collected from the environment, avoiding the containment stress. From August to September 2016, samples of fresh feces were collected from 90 cages in two breeding grounds, representing 180 birds. According to both analysis techniques the samples were negative for Salmonella spp., however, bacteria from the Enterobacteriaceae family: Escherichia coli, Cedecea sp. and Citrobacter freundii were detected. Continuous monitoring of breeding grounds is important since the pathogen investigated can be found in carrier birds and manifest itself in stressful situations presenting risks such as zoonosis and reduced bird health.
\end{abstract}

Keywords: wild birds, psittacine birds, intestinal pathogens, Enterobacteriaceae, zoonosis

\section{INTRODUÇÃO}

Os psitacídeos são aves da ordem Psittaciformes que se caracterizam por apresentarem bico superior curvo e bem desenvolvido e pés preênseis, zigodáctilos, possuindo os dígitos I e IV direcionados caudalmente e os dígitos II e III, cranialmente. Têm ampla distribuição geográfica, ocorrendo desde áreas tropicais até regiões frias. O Brasil é considerado o país mais rico em variedade de psitacídeos, com 80 espécies descritas, do total de 100 na América do Sul. Das 332 espécies relatadas, 148 ocorrem no Novo Mundo e 184 no Velho Mundo. A perda e

Recebido em 24 de fevereiro de 2017

Aceito em 22 de junho de 2017

E-mail: laumurer@hotmail.com 
a alteração de habitat, bem como o tráfico de fauna silvestre, colocaram muitas dessas aves em risco de extinção. A beleza de suas cores, sua inteligência, o potencial para serem treinados e a capacidade de imitar a voz humana fazem com que sejam muito procurados como animais de estimação (Godoy, 2007; Harcourt-Brown, 2010). Por meio de portarias específicas, o Instituto Brasileiro do Meio Ambiente e dos Recursos Renováveis (IBAMA) normatizou a criação e a comercialização de espécies silvestres nativas e, assim, é possível adquirir animais da fauna brasileira de maneira lícita (Allgayer e Cziulik, 2007).

Os papagaios são psitacídeos robustos, de cauda curta e bico grande, enquanto as araras variam de tamanho entre $30 \mathrm{~cm}$ da maracanã-pequena (Ara nobilis) até arara-azul (A. hyacinthinus) com $100 \mathrm{~cm}$, possuindo bico grande e cauda longa (Harcourt-Brown, 2010). O papagaio charão, Amazona pretrei, vive nas matas de araucária do Rio Grande do Sul (Sigrist, 2009); ameaçado pela captura de filhotes e perda de habitat, consta nas Listas das Espécies da Fauna Brasileira Ameaçadas de Extinção - 2014 na categoria vulnerável (VU) (Espécies..., 2014). O papagaioverdadeiro (Amazona aestiva) habita áreas semiabertas no Brasil Central, no Nordeste e em parte do Sudeste e a arara-canindé (Ara ararauna) é encontrada em florestas e matas desde a Amazônia até o Brasil centro-meridional (Sigrist, 2009). O termo "periquito" é usado para pequenos papagaios de cauda longa e graduada, distribuídos em sua maioria pelo Pacífico e pela Ásia (Harcourt-Brown, 2010).

As enterites bacterianas, comuns em psitacídeos, são atribuídas a alterações do microambiente intestinal e diminuição da resposta imune (Lopes et al., 2016). Entre as bactérias que causam doenças nos psitacídeos, as Gram negativas são as mais patogênicas (Godoy, 2007) e, entre elas, está a família Enterobacteriaceae, formada por bacilos com mais de 28 gêneros e de 80 espécies (Quinn et al., 2005). Os principais patógenos pertencentes a essa família, relatados em aves, são Salmonella spp., Escherichia coli e Yersinia $\mathrm{sp}$., os quais podem causar doenças entéricas e sistêmicas. Em menor número, são encontrados trabalhos científicos relacionados a outros microrganismos dessa família, tais como Shigella spp., Edwardsiella tarda, Proteus spp., Hafnia alvei, Serratia spp., Enterobacter cloacae,
Citrobacter freundii e Klebsiella pneumoniae (Allgayer et al., 2008; Lopes et al., 2016). Embora pouco relatado, segundo Godoy (2007), Citrobacter freundii apresenta alta patogenicidade, podendo desencadear bacteremia aguda seguida de morte, principalmente em aves jovens e imunossuprimidas. Esses agentes têm distribuição mundial, habitam o trato intestinal de animais e humanos e contaminam vegetação, solo e água (Quinn et al., 2005; Corrêa et al., 2013).

O gênero Salmonella é dividido em duas espécies: S. enterica e S. bongori, sendo a primeira dividida em seis subespécies: enterica, salamae, arizonae, diarizonae, houtenae e indica. As cepas são classificadas em sorovares baseados na diversidade de lipopolissacarídeos (LPS), antígenos (O) e antígeno flagelar (H). Atualmente, mais de 2.600 sorovares são reconhecidos (Guibourdenche et al., 2010; Terrestrial..., 2010). O sorotipo isolado de Psittaciformes com maior frequência é $S$. Typhimurium (Godoy, 2007; Harcourt-Brown, 2010), porém, em seu estudo, Lopes et al. (2014), ao utilizarem o método microbiológico convencional, isolaram $S$. Lexington, $S$. Saintpaul e $S$. Newport.

Água e alimentos contaminados são as principais fontes de infecção, mas animais cronicamente infectados, aves de vida livre, roedores e insetos também podem carrear o patógeno (Godoy, 2007). As aves afetadas podem ter morte súbita ou apresentar sinais inespecíficos, como diarreia aquosa profusa, polidipsia/poliúria, dispneia/pneumonia, depressão, anorexia e, ocasionalmente, sinais neurológicos. As aves tratadas podem recuperar-se, porém permanecem portadoras, com eliminação intermitente do patógeno (Godoy, 2007; Harcourt-Brown, 2010). Outro fator importante é a disseminação pelo ambiente, como a relatada por Kanashiro et al. (2002), que verificaram um caso de contaminação disseminada em um criadouro comercial de aves silvestres onde, por meio de método microbiológico, foi identificada Salmonella enterica subspécie enterica sorotipo 4, 5, 12: i: - em Agapornis (Agapornis roseicollis), Gold Diamond (Chloebia gouldiae) e Bivate (Stagonopleura guttata) mantidos em viveiros distintos. 
Com vista a aumentar o conhecimento sobre os psitacídeos e seus agentes infecciosos em animais de cativeiro, objetivou-se investigar a ocorrência de Salmonella spp. em psitacídeos na região central do Rio Grande do Sul, por meio do método bacteriológico convencional e da reação em cadeia da polimerase (PCR), utilizando-se amostras fecais do ambiente a fim de se evitar o estresse da contenção. Este trabalho reveste-se de especial importância visto que as salmoneloses, além dos prejuízos que podem causar aos criadores ao colocarem em risco a saúde do plantel, sendo zoonoses, representam perigo também para as pessoas que mantêm contato com as aves, seja por motivo de trabalho, seja como animais de companhia.

\section{MATERIAL E MÉTODOS}

O estudo foi realizado em dois criatórios de aves ornamentais da região central do Rio Grande do Sul. Um, onde são criadas diversas espécies de Psittaciformes da fauna silvestre exótica, e outro, licenciado pelo IBAMA para criação de psitacídeos da fauna silvestre nativa. As aves estavam alojadas em casais, recebendo ração comercial, mistura de sementes e água ad libitum, e apresentavam-se clinicamente saudáveis.

No período de agosto a setembro de 2016 foram realizadas coletas de fezes de 60 gaiolas de aves exóticas, com um casal em cada uma, e uma coleta de 30 amostras de fezes de aves nativas, mantidas em viveiros, em casais, totalizando 90 recintos, que representam 180 aves (Tab. 1).

Tabela 1. Relação das espécies de psitaciformes e amostragem utilizada, onde n representa o número de recintos coletados

\begin{tabular}{|c|c|c|c|}
\hline Espécie & Nome comum & $\mathrm{n}$ & $\%$ \\
\hline Amazona aestiva & Papagaioverdadeiro & 11 & 12,2 \\
\hline Amazona pretrei & Papagaio-charão & 17 & 18,9 \\
\hline Ara ararauna & Arara-canindé & 02 & 2,2 \\
\hline Barnardius barnardi & Periquito cloncurry & 01 & 1,1 \\
\hline Barnardius zonarius & Periquito-port-lincoln & 01 & 1,1 \\
\hline Bolborhynchus lineola & Periquito-catarina & 03 & 3,3 \\
\hline Forpus sp. & Forpus & 01 & 1,1 \\
\hline Lathamus discolor & Swift parrot & 02 & 2,2 \\
\hline Neopsephotus bourkii & Periquito-de-bourke & 08 & 8,9 \\
\hline Platycercus sp. & Rosela & 10 & 11,1 \\
\hline Poicephalus senegalus & Papagaio-do-senegal & 01 & 1,1 \\
\hline Polytelis alexandrae & Periquito-príncipe-de-gales & 02 & 2,2 \\
\hline Polytelis anthopeplus & Periquito-regente & 01 & 1,1 \\
\hline Polytelis swainsonii & Periquito Barraband & 01 & 1,1 \\
\hline Psephotus haematonotus & Red rumped & 21 & 23,3 \\
\hline Psittacula alexandri & Moustache & 01 & 1,1 \\
\hline Psittacula columboides & Periquito-de-malabar & 01 & 1,1 \\
\hline Psittacula cyanocephala & Cabeça-de-ameixa & 02 & 2,2 \\
\hline Psittacula krameri & Ring necked & 03 & 3,3 \\
\hline Purpureicephalus spurius & Periquito-red-capped & 01 & 1,1 \\
\hline Total & & 90 & 100 \\
\hline
\end{tabular}


Para a coleta das amostras, as gaiolas (ou viveiros) foram forradas com papel-alumínio. Logo após a defecação, as fezes foram coletadas com suabe estéril, passadas para kit de coleta com papel-filtro fornecido pelo laboratório e, então, o suabe foi colocado em tubo de ensaio contendo $10 \mathrm{~mL}$ de água peptonada a $1 \%$.

O material para exame bacteriológico foi conservado em caixa de isopor com gelo até chegar ao Núcleo de Estudos e Pesquisas em Animais Silvestres (NEPAS), do Laboratório Central de Diagnóstico de Patologias Aviárias (LCDPA) da Universidade Federal de Santa Maria (UFSM) para análise. Os kits de coleta para pesquisa pela reação em cadeia da polimerase $(\mathrm{PCR})$ foram mantidos à sombra por cerca de uma hora para secagem completa e remetidos a laboratório especializado, de acordo com as instruções do mesmo, em temperatura ambiente. A metodologia utilizada no diagnóstico pela PCR seguiu o protocolo de Freitas (2008).

No LCDPA foram realizadas análises microbiológicas qualitativas das amostras segundo a metodologia para Salmonella spp. utilizada na rotina do laboratório, adaptada de Brasil (2003) e Brasil (2011). As amostras que estavam em caldo de pré-enriquecimento não seletivo (água peptonada a 1\%) foram incubadas em estufa a $37^{\circ} \mathrm{C} / 20 \mathrm{~h}$. Após esse período, uma alíquota de $1 \mathrm{~mL}$ do caldo foi transferido a tubos de ensaio contendo $10 \mathrm{~mL}$ de caldo tetrationato (TT) acrescido de solução verde brilhante a $0,1 \%$ e iodo-iodeto; outra alíquota, de $100 \mu \mathrm{L}$, foi adicionada aos tubos contendo $10 \mathrm{~mL}$ de caldo Rappaport-Vassiliadis (RV), sendo incubados novamente em estufa a $37^{\circ} \mathrm{C} / 24 \mathrm{~h}$ e $42^{\circ} \mathrm{C} / 24 \mathrm{~h}$, respectivamente. Após esse período, com auxílio de alças estéreis descartáveis, os caldos de enriquecimento seletivo foram estriados em placas com meio ágar verde brilhante (AVB) e ágar xilose lisina desoxicolato (XLD) e levados à estufa a $37^{\circ} \mathrm{C} / 24 \mathrm{~h}$. Após o exame das placas, colônias morfologicamente compatíveis com Salmonella spp. foram selecionadas para a realização de triagem bioquímica, composta dos seguintes meios: "Triple Sugar Iron" (TSI),
"Lysine Iron Agar" (LIA), meio sulfeto indol motilidade (SIM), caldo ureia e ágar citrato de Simmons. Após incubação a $37^{\circ} \mathrm{C} / 24 \mathrm{~h}$, foi realizada a leitura e a interpretação das provas bioquímicas de acordo com Macfaddin (1999). Para efeito de comparação de resultados, todo o protocolo foi desenvolvido também com uma cepa de campo, controle positivo de Salmonella Gallinarum, previamente tipificada, pertencente à bacterioteca do LCDPA.

\section{RESULTADOS E DISCUSSÃO}

Os meios seletivos/indicadores AVB e XLD foram utilizados para diferenciar salmonelas de outros enteropatógenos. No ágar XLD, as colônias da maioria dos sorotipos de salmonelas são vermelhas com centros pretos e uma zona rosa-avermelhada pode ser vista no meio que envolve as colônias (Quinn et al., 2005; WHO Isolation..., 2010). Com base nessas informações, ao se analisarem as 90 placas contendo XLD, observou-se que, na maioria delas, o meio desenvolveu coloração amarelo intenso e, em apenas 15, o meio estava rosa ou vermelho. Embora em algumas dessas placas as colônias não apresentassem centro preto, tendo em vista que alguns sorovares de Salmonella spp. não manifestam essa característica, para evitar resultado falso negativo, optou-se por testar as 15 placas com a série bioquímica. Da mesma forma, foram selecionadas 11 placas com AVB, em que o meio apresentou coloração em tons de rosa, já que, de acordo com Quinn et al. (2005) e WHO (Isolation..., 2010), nesse meio, as colônias de salmonelas e o meio adjacente desenvolvem coloração rosa ou vermelha e outras enterobactérias aparecem em verde ou amarelo.

Das 26 amostras selecionadas (14,4\%), oito placas eram do criatório de aves nativas, sendo isolada, nas sete placas com XLD, Escherichia coli e, na placa com AVB, Cedecea sp. Do criatório de exóticas, foram 18 placas, verificando-se nas placas com XLD, a presença de Citrobacter freundii em cinco placas e de Cedecea sp. em três delas. No meio AVB, foram duas placas com Citrobacter freundii e oito com Cedecea sp. (Tab. 2). 
Investigação de...

Tabela 2. Resultados dos testes bioquímicos presuntivos para 26 amostras de fezes de Psittaciformes suspeitas de Salmonella spp. analisadas mediante os meios de cultura ágar xilose lisina desoxicolato (XLD) e ágar verde brilhante (AVB)

\begin{tabular}{lcccccccc}
\multirow{2}{*}{ Enterobactéria } & \multicolumn{3}{c}{ Nativas } & \multicolumn{3}{c}{ Exóticas } & \multirow{2}{*}{ Total } & \multirow{2}{*}{ Total (\%) } \\
\cline { 2 - 7 } & XLD & AVB & $\%$ & XLD & AVB & $\%$ & & 00 \\
\hline Escherichia coli & 07 & 00 & 87,5 & 00 & 00 & 00 & 07 & 26,9 \\
Cedecea sp. & 00 & 01 & 12,5 & 03 & 08 & 61,1 & 12 & 46,2 \\
Citrobacter freundii & 00 & 00 & 00 & 05 & 02 & 38,9 & 07 & 26,9 \\
Total & & 08 & 100 & & 18 & 100 & 26 & 100 \\
\hline
\end{tabular}

Nesta investigação, Salmonella spp. não foi isolada de nenhuma amostra submetida à análise microbiológica convencional e, da mesma forma, essa bactéria não foi detectada na PCR em nenhuma das 90 amostras. Esse resultado está de acordo com estudo realizado por Sareyyüpoğlu et al. (2008), que, ao analisarem 185 amostras de sete criatórios de periquitos-australianos, canários e outras espécies de aves, observaram a presença de Salmonella spp. nas espécies Serinus canaria, Fringilla montifringilla e Taeniopygia guttata, e nenhuma das 27 amostras de fezes de psitacídeos (periquitos-australianos) foi positiva para Salmonella spp. Porém, Tunca et al. (2012), ao avaliarem periquitos australianos (Melopsittacus undulatus) provenientes de três criatórios comerciais na Turquia, detectaram a presença de $S$. Gallinarum com taxa de mortalidade mais alta nessas aves comparada com outras espécies, o que mostra que esses psitacídeos são altamente susceptíveis ao patógeno. No presente estudo, que utilizou esse sorovar como controle positivo, foi observado que nenhuma amostra foi fenotipicamente semelhante na avaliação microbiológica.

Bezerra et al. (2013) analisaram 264 amostras de suabe de arrasto e suabes cloacais de periquitosaustralianos provenientes de pet shops e criadouros e, por meio do método microbiológico, constataram ausência de Salmonella spp. A justificativa dada para a ausência do patógeno foi relacionada com medidas sanitárias utilizadas pelos criadores, tais como limpeza diária dos bebedouros, comedouros, gaiolas e instalações, assim como o uso de água de torneira e de ração mantida em recipientes fechados. Em outro estudo, Keen et al. (2007), ao analisarem amostras de fezes de 22 aves (entre elas, três papagaios) de zoológicos dos Estados Unidos, obtiveram resultado negativo para Salmonella spp., atribuindo a baixa prevalência às excelentes condições das instalações e de manejo. Da mesma forma, nos criatórios testados neste estudo, boas práticas de manejo e ótimas condições das instalações poderiam ser apontadas como responsáveis por não favorecerem a presença do agente nos criatórios.

A baixa expressividade de resultados positivos para Salmonella spp. em amostras de aves silvestres é identificada desde muitos anos, como demonstrado em trabalho feito por Dorrestein et al. (1985), em que foram avaliadas 80 amostras fecais e 466 necropsias de Cacatuinae, Trichoglossinae e Pscittacinae, sendo positiva para Salmonella spp. apenas uma amostra fecal e oito materiais oriundos de necropsias. A microbiota predominante na amostragem era composta principalmente por Escherichia coli, Klebsiella spp., Enterobacter spp., Acinetobacter spp., Streptococcus, Staphylococcus e Lactobacillus. Corrêa et al. (2013), quando analisaram 44 amostras provenientes de psitacídeos da fauna nativa de cativeiro (15 fragmentos de órgãos de aves necropsiadas e 29 suabes de cloaca e inglúvio), não encontraram nenhuma amostra positiva para Salmonella spp., porém 28 amostras $(63,6 \%)$ foram positivas no exame microbiológico para Escherichia coli.

Em estudo sobre a prevalência de enterobactérias isoladas de Psittaciformes oriundos do tráfico da fauna silvestre brasileira, Lopes et al. (2015) analisaram 167 suabes cloacais e isolaram enterobactérias em 119 indivíduos (71,3\%), sendo Escherichia coli a mais prevalente $(46,5 \%)$ e, entre as menos prevalentes, Salmonella Saintpaul foi isolada de uma ave (0,6\%). Hidasi et al. (2013), quando avaliaram amostras fecais de 300 papagaios capturados ilegalmente no Brasil, por meio de exame bacteriológico convencional, obtiveram um total de 508 isolados, sendo 172 Escherichia coli (33,9\% dos isolados; $57,3 \%$ dos indivíduos); 153 Enterobacter spp. (30,1\% dos isolados; 51,0\% dos indivíduos); 89 Klebsiella spp. (17,5\% dos 
isolados; 29,7\% dos indivíduos); 59 Citrobacter spp. (11,6\% dos isolados; $19,7 \%$ dos indivíduos), 21 Proteus vulgaris $(4,2 \%$ dos isolados; $7,0 \%$ dos indivíduos), cinco Providencia alcalifaciens $(0,98 \%$ dos isolados; $1,67 \%$ dos indivíduos $)$, cinco Serratia sp. $(0,98 \%$ dos isolados; $1,67 \%$ dos indivíduos), três Hafnia aivei $(0,59 \%$ dos isolados; $1,00 \%$ dos indivíduos) e uma Salmonella sp. (0,20\% dos isolados; $0,33 \%$ dos indivíduos). No presente estudo, obteve-se uma alta prevalência de Escherichia coli $(87,5 \%)$ no criatório de aves nativas, o que está de acordo com os trabalhos citados anteriormente para essa enterobactéria.

Lopes et al. (2014), mediante o uso de métodos microbiológicos convencionais, avaliaram suabes cloacais de 182 psitacídeos e obtiveram três $(1,65 \%)$ resultados positivos: Amazona aestiva (Salmonella Lexington), Arachloroptera (Salmonella Saintpaul) e Melopsittcus undulatus (Salmonella Newport), e consideraram baixa prevalência de Salmonella sp. em Psittaciformes mantidos em criatórios comerciais e conservacionistas da Região Metropolitana de Fortaleza. Marietto-Gonçalves et al. (2010) avaliaram 103 psitacídeos oriundos do tráfico de animais e em processo de reabilitação para soltura e detectaram a presença de Salmonella enterica subespécie enterica sorotipo Enteritidis em três (2,9\%) Amazona aestiva, espécie de psitacídeo habitualmente traficada e encontrada em residências. Nemeth et al. (2016) realizaram estudo retrospectivo de 827 amostras aviárias (112 Psittaciformes, 22 Passeriformes, 18 Galliformes, 10 Anseriformes e seis Columbiformes), recebidas na University of Georgia, Pathology Department and Athens Veterinary Diagnostic Laboratory entre 2006 e 2011, e apenas cinco foram positivas para Salmonella spp., o que confirma a baixa prevalência dessa bactéria nos diagnósticos laboratoriais dessas ordens taxonômicas.

As enterobactérias isoladas no presente estudo como suspeitas de Salmonella e não confirmadas pelas provas bioquímicas são citadas na literatura como possuidoras de características fenotípicas semelhantes a essa bactéria, o que reforça a necessidade da caracterização bioquímica, sorológica e molecular dos isolados. Segundo
Delgado et al. (2013), C. freundii apresenta grande versatilidade na morfologia de suas colônias, assim como no seu comportamento bioquímico, antigênico e patológico, o que dificulta a identificação e faz com que seja frequentemente confundida com Salmonella enterica e Escherichia coli.

Uma hipótese para os resultados negativos obtidos na investigação de Salmonella spp. por meio dos métodos microbiológicos convencionais e PCR é que o isolamento de Salmonella em fezes de animais pode ser dificultado quando há infecção subclínica, com eliminação de pequeno número desse agente nas fezes (WHO Isolation..., 2010). No presente estudo, as aves apresentavam-se clinicamente sadias. Além disso, a população de salmonelas é muito menor do que de outras bactérias da microbiota entérica (WHO Isolation..., 2010). Outro fator a ser considerado é a possibilidade da excreção intermitente do agente, o qual poderia estar ausente no momento da coleta das fezes, impossibilitando seu isolamento e identificação naquelas amostras (Allgayer et al., 2008; Harcourt-Brown, 2010; Lopes et al., 2014; Lopes et al., 2016).

\section{CONCLUSÕES}

No presente estudo, não foi isolada Salmonella spp., mas foram detectadas três outras enterobactérias, sendo pelo menos duas delas potencialmente patogênicas (Escherichia coli e Citrobacter freundii). O método microbiológico convencional e a PCR indicaram o mesmo resultado negativo para as amostras analisadas, demonstrando equidade de $100 \%$. Considera-se importante a continuidade do monitoramento dos criatórios, já que o resultado negativo para as amostras não significa a ausência de Salmonella spp., podendo estar em aves portadoras e se manifestar em situações de estresse, representando riscos enquanto zoonose $\mathrm{e}$ prejuízos à saúde das aves.

\section{AGRADECIMENTOS}

À Coordenação de Aperfeiçoamento de Pessoal de Nível Superior (Capes), pela concessão de bolsa de doutorado ao autor Laurete Murer. 


\section{REFERÊNCIAS}

ALLGAYER, M.C.; CZIULIK, M. Reprodução de psitacídeos em cativeiro. Rev. Bras. Reprod. Anim., v.31, p.344-350, 2007.

ALLGAYER, M.C.; LIMA-ROSA, C.A.V.; WEIMER, T.A. et al. Molecular diagnosis of Salmonella species in captive psittacine birds. Vet. Rec., v.162, p.816-819, 2008.

BEZERRA, W.G.A.; CARDOSO, W.M.; TEIXEIRA, R.S.C. et al. Survey of Salmonella sp. in Budgerigars (Melopsittacus undulatus) in Fortaleza, Brazil. Acta Sci. Vet., v.41, p.1-7, 2013.

BRASIL. Ministério da Agricultura, Pecuária e Abastecimento. Métodos analíticos oficiais para análises microbiológicas para controle de produtos de origem animal e água. Instrução Normativa n.62, de 26 de agosto de 2003 MAPA. Diário Oficial da União, Brasília, 18 set. 2003.

BRASIL. Ministério da Saúde. Secretaria de Vigilância em Saúde. Manual técnico de diagnóstico laboratorial de Salmonella spp.: diagnóstico laboratorial do gênero Salmonella. Brasília: Fundação Oswaldo Cruz, 2011. p.1639.

CORRÊA, I.M.; FLORES, F.; SCHNEIDERS, G.H. et al. Detecção de fatores de virulência de Escherichia coli e análise de Salmonella spp. em psitacídeos. Pesqui. Vet. Bras., v.33, p.241-246, 2013.

DELGADO, G.; SOUZA, V.; MORALES, R. et al. Genetic characterization of atypical citrobacter freundii. PLOS ONE, v.8, p.e74120, 2013.

DORRESTEIN, G.M.; BUITELAAR, M.N.; VAN DER HAGE, M.H.; ZWART, P. Evaluation of a bacteriological and mycological examination of psittacine birds. Avian Dis., v.29, p.951-962, 1985.

ESPÉCIES ameaçadas - 2014. Disponível em: $<$ http://www.icmbio.gov.br/portal/faunabrasileira /lista-de-especies>. Acessado em: 13 jan. 2017.
FREITAS, C.G. Adaptação da técnica de PCR múltipla para a identificação de Salmonella sp. e dos sorotipos Typhi, Enteritidise Typhimurium por em carcaças e miúdos de aves comercializadas no distrito Federal. 2008. 65f. Dissertação (Mestrado em Saúde Animal) Programa de Pós-Graduação em Saúde Animal, Universidade de Brasília, Brasília, DF.

GODOY, S.N. Psittaciformes (arara, papagaio, periquito). In: CUBAS, Z.S.; SILVA, J.C.R.; CATÃO-DIAS, J.L. Tratado de animais selvagens-medicina veterinária. São Paulo: Roca, 2007. p.222-251.

GUIBOURDENCHE, M.; ROGGENTIN, P.; MIKOLEIT, M. et al. Supplement 2003-2007 (no. 47) to the White-Kauffmann-Le Minor scheme. Res. Microbiol., v.161, p.26-29. 2010.

HARCOURT-BROWN, N.H. Aves psitaciformes. In: TULLY JR., T.N.; DORRESTEIN, G.M.; JONES, A.K. Clínica de aves. 2.ed. Rio de Janeiro: Elsevier, 2010. p.122123.

HIDASI, H.W.; HIDASI NETO, J.; MORAES, D.M.C. et al. Enterobacterial detection and Escherichia Coli antimicrobial resistance in parrots seized from the illegal wildlife trade. $J$. Zoo Wildl. Med., v.44, p.1-7, 2013.

KANASHIRO, A.M.I.; CASTRO, A.G.M.; CARDOSO, A.L.S.P. et al. Persistência de Salmonella sp. após antibioticoterapia em psitacídeos pertencentes a um criadouro comercial. Arq. Inst. Biol., v.69, p.99-101, 2002.

KEEN, J.E.; DURSO, L.M.; MEEHAN, T.P. Isolation of Salmonella enterica and shigatoxigenic Escherichia coli O157 from feces of animals in public contact areas of United States zoological parks. Appl. Environ. Microbiol., v.73, p.362-365, 2007.

LOPES, E.S.; CARDOSO, W.M.; ALBUQUERQUE, Á.H. et al. Isolation of Salmonella spp. in captive Psittaciformes from zoos and a commercial establishment of Fortaleza, Brazil. Arq. Bras. Med. Vet. Zootec., v.66, p.965-968, 2014. 
LOPES, E.S.; MACIEL, W.C.; ALBUQUERQUE, Á.H. et al. Prevalence and antimicrobial resistance profile of enterobacteria isolated from psittaciformes of illegal wildlife trade. Acta Sci. Vet., v.43, p.1-9, 2015.

LOPES, E.S.; MACIEL, W.C.; TEIXEIRA, R.S.C. et al. Isolamento de Salmonella spp. e Escherichia coli de psittaciformes: relevância em saúde pública. Arq. Inst. Biol., v.83, p.1-10, 2016.

MACFADDIN, J.F. Biochemical tests for identification of medical bacteria. Philadelphia: Lippincott, Williams \& Wilkins, 1999. p.732802.

MARIETTO-GONÇALVES, G.A; ALMEIDA, S.M.; LIMA, E.T. et al. Isolation of Salmonella enterica Serovar Enteritidis in Blue-Fronted Amazon Parrot (Amazona aestiva). Avian Dis., v.54, p.151-155, 2010.

NEMETH, N.M.; GONZALEZ-ASTUDILLO, V.; OESTERLE, P.T.; HOWERTH, E.W. A 5-Year retrospective review of avian diseases diagnosed at the Department of Pathology, University of Georgia. J. Comp. Pathol., p.1-16, 2016. Available in: $<$ http://dx.doi.org/10.1016/j.jcpa.2016.05.006>. Accessed in: 05 Feb. 2017.
QUINN, P.J.; MARKEY, B.K.; CATER, M.E. et al. (Eds.). Microbiologia veterinária e doenças infecciosas. Porto Alegre: Artmed, 2005. p.115130.

SAREYYÜPOĞLU， B.; ÇELIK， O.K.; CANTEKIN, Z. et al. Polymerase chain reaction detection of Salmonella spp. in fecal samples of pet birds. Avian Dis., v.52, p.163-167, 2008.

SIGRIST, T. Guia de campo avis Brasilis avifauna brasileira. São Paulo: Avis Brasilis, 2009. 600p.

TERRESTRIAL manual, 2010. Available in: $<$ https://web.oie.int/eng/normes/MMANUAL/20 08/pdf/2.09.09_SALMONELLOSIS.pdf $>$. Accessed in: 03 Feb. 2017.

TUNCA, R.; TOPLU, N.; KIRKAN, S. et al. Pathomorphological, immunohistochemical and bacteriological findings in budgerigars (Melopsittacus undulatus) naturally infected with S. Gallinarum. Avian Pathol., v.41, p.203-209, 2012.

WHO Global Foodborne Infections Network. Laboratory Protocol "Isolation of Salmonella spp. From Food and Animal Faeces", 2010. Available in: $<$ http://www.antimicrobialresistance.dk/data/ima ges/protocols/isolation_of_salm_220610.pdf $>$. Accessed in: 03 Feb. 2017. 